Article

\title{
Density Functional Theory Analysis of the Adsorption Interactions of Carbon Impurities in Coal-associated Kaolinite
}

\author{
Fangqin Lu ${ }^{1,2}$, Lingyun Liu ${ }^{1,2, * \mathbb{D}}$, Fanfei Min ${ }^{2}$, Jun Chen ${ }^{1,2}$ and Mingxu Zhang ${ }^{2}$ \\ 1 State Key Laboratory of Mining Response and Disaster Prevention and Control in Deep Coal Mines, \\ Huainan 232001, China; fqlu0816@163.com (F.L.); jchen412@126.com (J.C.) \\ 2 College of Material Science and Engineering, Anhui University of Science and Technology, Huainan 232001, \\ China; ffmin@aust.edu.cn (F.M.); mxzhang@aust.edu.cn (M.Z.) \\ * Correspondence: lyunliu@163.com
}

Received: 25 September 2019; Accepted: 18 October 2019; Published: 1 November 2019

\begin{abstract}
Kaolinite is a difficult-to-float clay existing in coal slurries which negatively impacts coal flotation. A better understanding of its adsorption behavior would improve coal-slurry processing. Carbon impurities in the kaolinite can affect this behavior. The appearance and elemental surface composition of the carbon impurities precipitated by kaolinite oxidative treatment were microscopically analyzed, and their chemical speciation and relative $\mathrm{C}$ and $\mathrm{O}$ contents were probed. The mechanisms of adsorption on the main kaolinite cleavage planes ((001) and (001) surfaces) for two carbon-impurity structural models, a phenolic hydroxyl unit $(\mathrm{Ph}-\mathrm{OH})$ and carbon hydroxyl unit $(\mathrm{C}-\mathrm{OH})$, were considered using density functional theory methods. The carbon impurities consisted mainly of $\mathrm{C}$ and $\mathrm{O}$, with $\mathrm{C}$ present mostly as $\mathrm{C}-\mathrm{C}, \mathrm{C}-\mathrm{H}$, and $\mathrm{C}-\mathrm{O}$ species, and $\mathrm{O}$ existing mainly in $-\mathrm{OH}$ and $\mathrm{C}-\mathrm{O}$ structures. Both $\mathrm{Ph}-\mathrm{OH}$ and $\mathrm{C}-\mathrm{OH}$ units adsorbed stably on the kaolinite (001) and $(00 \overline{1})$ surfaces through hydrogen bonding between the hydroxyl groups and surfaces. A strong electrostatic attraction occurred between the $\mathrm{Ph}-\mathrm{OH}$ benzene ring and kaolinite surfaces, whereas the carbon ring in $\mathrm{C}-\mathrm{OH}$ did not interact with either surface. Finally, for both units, adsorption on the kaolinite (001) surface was more stable than on the (001) surface.
\end{abstract}

Keywords: coal-associated kaolinite; carbon impurity; density functional theory; adsorption mechanism

\section{Introduction}

Coal-associated kaolinite is one of the major clay minerals in coal-water slurries [1]. It is fine-grained with high surface electronegativity, and strong hydration films readily form on the particle surfaces [2]. The surface hydration films strengthen the hydration repulsion as well as steric hindrance effects among the particles in the coal slurries. These effects, combined with the electrostatic repulsion caused by the large number of negative charges on the particle surfaces, help maintain the stability of fine kaolinites in coal slurries [3,4], which makes it difficult for the kaolinite to aggregate and settle, and thus, seriously affects the sedimentation and clarification of coal-water slurries. Meanwhile, the hydration film can also increase the viscosity of kaolinite particle-fluid suspensions [5], thus further reducing the efficiency of subsequent coal-slurry dewatering.

Through experiments and theoretical calculations, Cui et al. [6] found that an important premise for the separation of fine kaolinite is to regulate the structural properties of its interface. The main method of regulation is to add surfactants, such as cationic amine salts or quaternary ammonium salts, which regulate the hydrophobicity of the kaolinite surfaces [7]. To more deeply understand the functional mechanism, the interactions of the reagent at the kaolinite interface must be explored 
from a microscopic viewpoint at the molecular/atomic level. Density functional theory (DFT) and DFT-based first-principles calculation methods are widely applied as effective theoretical tools for the calculation of mineral structures and their surface interactions [8]. For example, Wang et al. [9] applied DFT to find that 2,4-dinitrotoluene adsorbs on fine kaolinite surfaces mainly through the formation of hydrogen bonds. Also using DFT methods, Chen et al. [10,11] simulated the adsorption of amine/ammonium cations on kaolinite (001) and (001) surfaces, and found that adsorption was the joint result of electrostatic attraction and the formation of hydrogen bonds, with the former as the major driving force.

Currently, researchers who have applied DFT to study surface adsorption in kaolinite have established simulations based on a perfect bulk kaolinite lattice, with few studies accounting for the occurrence of impurities in the kaolinite. Carbon impurities are a common contaminant type in coal-associated kaolinite. In the present study, scanning electron microscopy/energy dispersive spectrometry (SEM-EDS) and X-ray photoelectron spectroscopy (XPS) analyses were performed to determine the major elemental constituents of the carbon impurities and the structure and relative contents of the $\mathrm{C}$ and $\mathrm{O}$ elements. Subsequently, two typical structural models were constructed for the carbon impurities, and DFT was applied to simulate the adsorption mechanism of each unit on the kaolinite (001) and $(00 \overline{1})$ surfaces so as to determine the adsorption configuration. The results of the present study can provide a theoretical basis for the further understanding of actual adsorption on the surface of kaolinite in coal slurries.

\section{Materials and Methods}

\subsection{Materials}

Coal-associated kaolinite samples from Anhui Golden Rock Kaolin Co., Ltd. were used in the experiments, in addition to hydrogen peroxide $(9.8 \mathrm{~mol} / \mathrm{L})$ as the oxidizing agent and deionized water.

The samples were evaluated by scanning electron microscopy (Hitachi S-3000N, Tokyo, Japan), energy dispersive spectrometry (Oxford, Oxford, 51-XMX, USA), X-ray photoelectron spectrometry (Thermo Scientific ESCALAB 250Xi, Massachusetts, USA.), and pH meter (Lenci, PHS-3C, Shanghai, China).

\subsection{SEM-EDS Analysis}

To prepare the specimens for SEM-EDS analysis, crude kaolinite powder ( $375 \mathrm{~g}$, sifted through 120-mesh dry sieve) was placed in a $1 \mathrm{~L}$ beaker and evenly mixed with $\mathrm{H}_{2} \mathrm{O}_{2}(150 \mathrm{~mL})$; the mixture was allowed to stand for $24 \mathrm{~h}$ for adequate oxidation. Subsequently, the mixture was heated in a $60^{\circ} \mathrm{C}$ water bath to decompose the residual $\mathrm{H}_{2} \mathrm{O}_{2}$, deionized water was added to make up the volume to $1 \mathrm{~L}$, and the mixture was allowed to stand for $10 \mathrm{~h}$. Finally, the atrament floating on the surface of the suspension was removed and dried for SEM-EDS analysis. Under the conditions of low vacuum, an accelerating voltage of $13 \mathrm{kV}$, and a working distance (WD) of $8 \mathrm{~mm}$, SEM was used to observe the appearance of the carbon structures precipitated from the coal-associated kaolinite, and EDS was used in combination with SEM to carry out semi-quantitative analysis of the elements on the sample surface through point analysis and surface analysis. The SEM-EDS analysis method can be found elsewhere [12].

\subsection{XPS Analysis}

Samples for XPS analysis were prepared by immersing and stirring coal-associated kaolinite in deionized water for $6 \mathrm{~h}$. The atrament that precipitated from the water was placed on a qualitative filter paper. After vacuum filtration, the sample was dried at $40^{\circ} \mathrm{C}$ and tabletted. The sample was subjected to XPS analysis under ultra-vacuum conditions $\left(<1 \times 10^{-9} \mathrm{mbar}\right)$ using the ESCALAB 250Xi instrument with a monochromatized $\mathrm{Al}$ target for energy spectrum analysis $(\mathrm{Al} \mathrm{K} \alpha, 0=1486.6 \mathrm{eV})$. The pass energy was $20 \mathrm{eV}$, the energy step size was $0.05 \mathrm{eV}$, and the spot size was $900 \mu \mathrm{m}$. 


\subsection{DFT Simulation Method}

The CASTEP (Cambridge Sequential Total Energy Package) module of Materials Studio 8.0 was used for the calculations [13]. The Perdew-Burke-Ernzerhof generalized gradient approximation (GGA-PBE) was applied as the exchange-correlation functional for geometry optimization of the bulk kaolinite [14], with the energy cut-off of the plane wave set at $400 \mathrm{eV}$. An ultra-soft pseudopotential was used to delineate the interaction between the valence electrons and ion core [15]. The Broyden-Fletcher-Goldfarb-Shanno (BFGS) algorithm was applied for the optimization and property calculations of the model, with the self-consistent field (SCF) tolerance set at $2.0 \times 10^{-6}$ eV/atom [16]. The Grimme method [17] was used for DFT-D (Density functional theory-dispersion) dispersion corrections, which has been found to be important in characterizing the adsorption of molecules on the slab model. The convergence criteria for geometry optimization were as follows: maximum displacement of $2 \times 10^{-4} \mathrm{~nm}$; maximum force tolerance of $0.05 \mathrm{eV} / \mathrm{A}$; maximum stress of $0.1 \mathrm{GPa}$; and energy change tolerance of $2.0 \times 10^{-5} \mathrm{eV} /$ atom. Electron density difference analysis was performed by Edit Sets to define the density differences of different carbon structural units in each adsorption configuration, and then the electron density difference map was derived by Analysis in CASTEP module.

The supercell surface model was cleaved from the (001) surface of the unit cell. A $2 \times 1 \times 1$ supercell model was constructed from the (001) surface, and a $1 \times 2 \times 1$ supercell model was constructed from the $(00 \overline{1})$ surface, where a $20 \AA$ vacuum slab was added. For the choice of k-points in the Monkhorst-Pack grid [18], the bulk was set as $(2 \times 2 \times 1)$ and the surface model as the gamma point. The valence electrons chosen for the pseudopotential calculations of the atoms were $\mathrm{Si} 3 s^{2} 3 p^{2}, \mathrm{Al} 3 s^{2} 3 p, O 2 s^{2} 2 p^{4}$, and $\mathrm{H}$ 1s. The lattice parameters of the optimized bulk kaolinite are shown in Table 1. As the error between the optimized results for the bulk kaolinite under the calculation conditions and the optimized simulation data and experimental results of other researchers were within $2.00 \%$, the results of the present paper are proven to be reasonable.

Table 1. Optimized results for the bulk kaolinite.

\begin{tabular}{cccccccc}
\hline \multirow{2}{*}{ Computational Parameter } & \multicolumn{3}{c}{ Lattice Parameters/Å } & \multicolumn{3}{c}{ Cell Angles/ } & \multicolumn{2}{c}{\begin{tabular}{c} 
Current \\
Cell \\
\cline { 2 - 7 }
\end{tabular}} & $\mathbf{a}$ & $\mathbf{b}$ & $\mathbf{c}$ & $\boldsymbol{\alpha}$ & $\boldsymbol{\beta}$ & $\boldsymbol{\gamma}$ & Volume/Å3 \\
\hline GGA/400 eV & 5.196 & 9.007 & 7.372 & 93.029 & 105.983 & 89.866 & 331.221 \\
(GGA/700 eV) [19] & 5.196 & 9.021 & 7.485 & 91.700 & 104.720 & 89.780 & 339.170 \\
Experimental test value [20] & 5.153 & 8.942 & 7.391 & 91.926 & 105.046 & 89.797 & 329.910 \\
\hline
\end{tabular}

The adsorption stability of the two carbon structural units adsorbed on the surface of kaolinite can be expressed using the adsorption energy Eads, with a higher value indicating higher adsorption stability. The adsorption energy can be calculated using Equation (1):

$$
E_{\text {ads }}=E_{\text {total }}-\left(E_{\text {adsorbate }}+E_{\text {surface }}\right),
$$

where $E_{\text {adsorbate }}$ is the energy of the adsorbate before adsorption, $E_{\text {surface }}$ is the energy of the mineral surface before adsorption, and $\mathrm{E}_{\text {total }}$ is the total energy of the stable system after adsorption.

The $\mathrm{Dmol}^{3}$ module was used for energy optimization of the optimized kaolinite surface model and carbon structural units and for the calculation of their frontier orbital properties, and the gamma point was set as the K-point. The parameters for the calculations of the frontier orbitals were as follows: GGA-PBE was set as the exchange-correlation functional; the effective core potentials and DNP (Double numeric with polarization) basis set were used; the orbital cut-off quality was set as fine; and the SCF tolerance was set as $1.0 \times 10^{-6} \mathrm{eV} /$ atom. 


\section{Results and Discussion}

\subsection{SEM-EDS and XPS Analyses of Carbon Impurities in Coal-Associated Kaolinite}

According to the literature [21], the carbon impurities in coal-associated kaolinite can be removed by immersing the kaolinite in the oxidizing agent $\mathrm{H}_{2} \mathrm{O}_{2}$. To prove that the atrament precipitated from the $\mathrm{H}_{2} \mathrm{O}_{2}$-immersed kaolinite consisted of carbon impurities (the atrament is partly oxidized when immersed in $\mathrm{H}_{2} \mathrm{O}_{2}$ ), the kaolinite was oxidatively treated, and the atrament separated and dried. SEM-EDS was used to analyze its appearance and surface elemental composition, with the results shown in Figure 1 and Table 2.
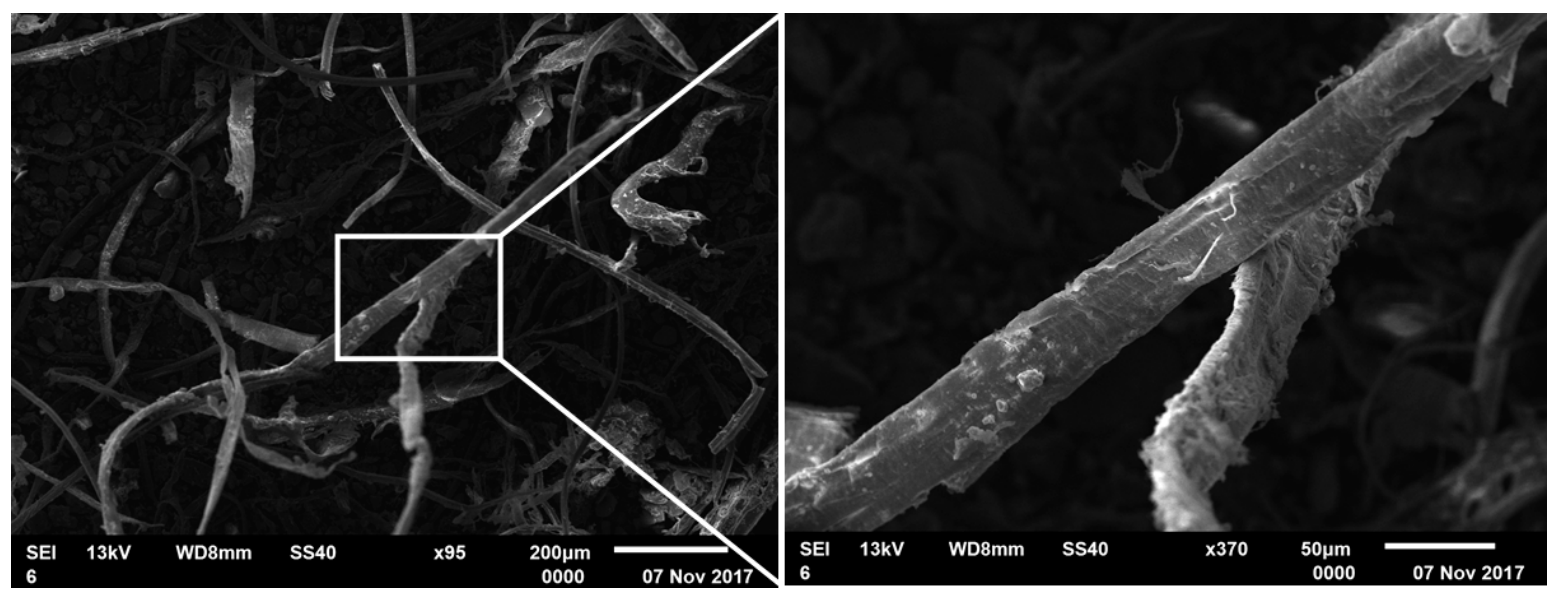

Figure 1. SEM (Scanning electron microscope) image of atrament in kaolinite; the panel to the right shows an enlargement of the box indicated at left.

Table 2. EDS (Energy dispersive X-ray spectroscopy) analysis of atrament in kaolinite (W\% and A\% represents the weight concentration and atomic concentration, respectively).

\begin{tabular}{cccccccccc}
\hline \multirow{2}{*}{ Analysis Method } & \multicolumn{2}{c}{$\mathbf{C}$} & \multicolumn{2}{c}{$\mathbf{O}$} & \multicolumn{3}{c}{ Al } & \multicolumn{2}{c}{ Si } \\
\cline { 2 - 10 } & $\mathbf{W} \%$ & $\mathbf{A} \%$ & $\mathbf{W} \%$ & $\mathbf{A} \%$ & $\mathbf{W} \%$ & $\mathbf{A} \%$ & $\mathbf{W} \%$ & $\mathbf{A} \%$ \\
\hline Surface analysis & 80.45 & 84.61 & 19.41 & 15.33 & 0.14 & 0.06 & 0 & 0 \\
Point analysis & 50.95 & 58.2 & 48.35 & 41.45 & 0.35 & 0.18 & 0.35 & 0.17 \\
Average & 65.7 & 71.405 & 33.88 & 28.39 & 0.245 & 0.12 & 0.175 & 0.085 \\
\hline
\end{tabular}

Figure 1 shows the SEM image of the atrament precipitated from the $\mathrm{H}_{2} \mathrm{O}_{2}$-immersed coal-associated kaolinite. The black impurities in the kaolinite formed filaments after immersion and oxidation by $\mathrm{H}_{2} \mathrm{O}_{2}$. Table 2 shows the EDS analysis results for the atrament; clearly, the atrament surface was mainly composed of $\mathrm{C}$ and $\mathrm{O}$ species, with trace amounts of $\mathrm{Al}$ and $\mathrm{Si}$. The $\mathrm{Al}$ and $\mathrm{Si}$ traces and a portion of the $\mathrm{O}$ species originated from a small amount of fine kaolinite particles mixed in the atrament, while another part of the $\mathrm{O}$ content stemmed from the oxidation of the atrament by $\mathrm{H}_{2} \mathrm{O}_{2}$. These compositional results ( $\mathrm{C}$ as the major component, $\mathrm{O}$ as the minor) confirm that the atrament consisted of carbon impurities.

As the density of the carbon impurities was lower than that of kaolinite, the water sieve method was used to separate the carbon impurities for XPS analysis (the prepared samples did contain some kaolinite, as complete separation could not be achieved). As shown in Table 3, the atomic concentration of $\mathrm{C}$ component in carbon impurity was much higher than that in the kaolinite sample. This indicates that the $C$ element in the kaolinite sample was mainly derived from the carbon impurities, which was consistent with SEM-EDS results. 
Table 3. Atomic concentration of each element in kaolinite sample and carbon impurity.

\begin{tabular}{cccccc}
\hline \multirow{2}{*}{ Sample } & \multicolumn{5}{c}{ Atomic Concentration/\% } \\
\cline { 2 - 6 } & C 1s & O 1s & Si 2p & A1 2p & Fe 2p \\
\hline Carbon impurity & 29.93 & 31.68 & 18.12 & 10.94 & 9.33 \\
Kaolinite sample & 11.15 & 50.16 & 19.75 & 14.21 & 4.73 \\
\hline
\end{tabular}

Based on binding energy (BE) and peak attribute reference data for C 1s [22-25] and O 1s [26,27], the XPSPEAK4.1 program was used for $\mathrm{C} 1 \mathrm{~s}$ and $\mathrm{O} 1$ s peak fitting, with the results shown in Figures 2 and 3 , respectively. The $\mathrm{C}$ atoms on the surface of the kaolinitic carbon impurities existed mainly in the forms of $\mathrm{C}-\mathrm{C}, \mathrm{C}-\mathrm{H}, \mathrm{C}-\mathrm{O}, \mathrm{C}=\mathrm{O}$, and $\mathrm{COO}-$ structures. As shown in Figure 2, there are three characteristic peaks of carbon structures, which belong to the $\mathrm{C}-\mathrm{C}$ structure, $\mathrm{C}-\mathrm{H}$ structure, and $\mathrm{C}-\mathrm{O}$ structure based on the ascending order of the position of electron binding energy. The $\mathrm{O}$ atoms on the impurities' surfaces are represented by the two characteristic peaks for $-\mathrm{OH}$ and $\mathrm{C}-\mathrm{O}$, again in increasing $\mathrm{BE}$ order, as well as peaks for $\mathrm{Si}(\mathrm{OH})_{4}$ and $\mathrm{Al}(\mathrm{OH})_{3}$ species present in the admixed kaolinite (Figure 3).

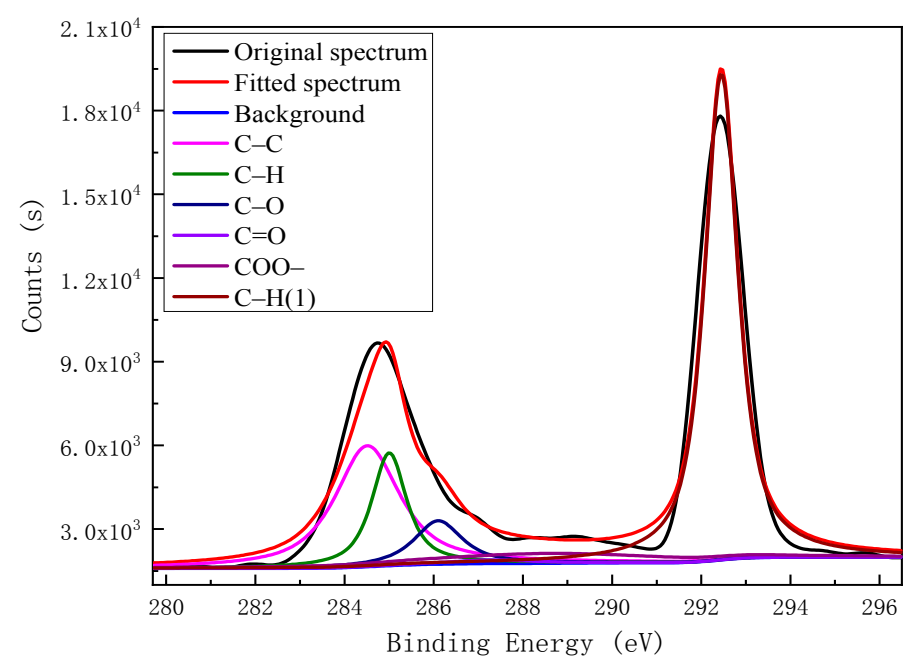

Figure 2. Fitted C 1s X-ray photoelectron spectroscopy (XPS) spectrum for the surface of carbon impurities in kaolinite.

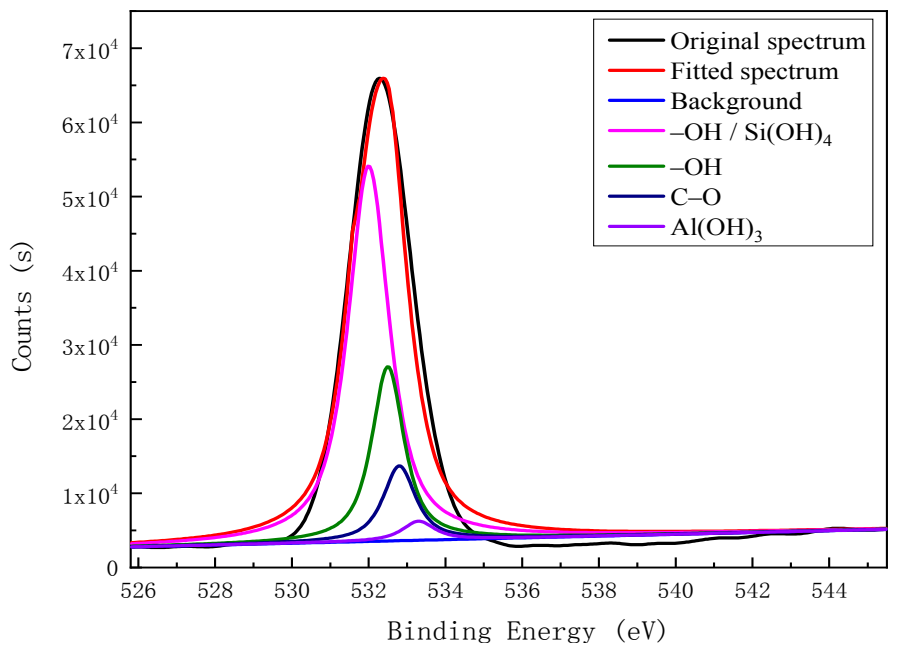

Figure 3. Fitted O 1s XPS spectrum for the surface of carbon impurities in kaolinite. 
Table 4 shows the surface functional groups and their relative contents in the kaolinitic carbon impurities within a depth of $10 \mathrm{~nm}$ from the surface. Carbon-containing species on the impurity surfaces mainly included $\mathrm{C}-\mathrm{C}$ and $\mathrm{C}-\mathrm{H}$ structures, as well as some $\mathrm{COO}-, \mathrm{C}-\mathrm{O}$, and $\mathrm{C}=\mathrm{O}$ structures. Oxygen-bearing functional groups on the carbon impurities' surfaces contained $-\mathrm{OH}$ and $\mathrm{C}-\mathrm{O}$ structures, with the relative content of the former exceeding that of the latter.

Table 4. Carbon and oxygen species and relative contents in kaolinitic carbon impurity oxides.

\begin{tabular}{ccccc}
\hline Element & Binding Energy/eV & $\begin{array}{c}\text { Functional } \\
\text { Group }\end{array}$ & Peak Area & Relative Content \% \\
\hline \multirow{4}{*}{ C 1s } & 284.50 & $\mathrm{C}-\mathrm{C}$ & $10,971.27$ & 23.96 \\
& 284.99 & $\mathrm{C}-\mathrm{H}$ & 5480.877 & 11.97 \\
& 286.10 & $\mathrm{C}-\mathrm{O}$ & 2914.683 & 6.36 \\
& 287.30 & $\mathrm{C}=\mathrm{O}$ & 442.6801 & 0.97 \\
& 288.60 & $\mathrm{COO}-$ & 3266.749 & 49.13 \\
\hline \multirow{2}{*}{$\mathrm{O} 1 \mathrm{~s}$} & 292.50 & $\mathrm{C}-\mathrm{H}$ & $22,716.64$ & 46.46 \\
& 531.90 & $-\mathrm{OH}, \mathrm{Si}(\mathrm{OH})_{4}$ & $95,055.25$ & 16.88 \\
& 532.40 & $-\mathrm{OH}$ & $34,541.36$ & 24.50 \\
\hline
\end{tabular}

\subsection{Occurrence of $C$ Element in Coal-Associated Kaolinite}

Based on the XPS analysis results for the carbon impurities in kaolinite, we established two typical carbon-impurity structural models, the $\mathrm{Ph}-\mathrm{OH}$ (3-methyl-Phenol) and $\mathrm{C}-\mathrm{OH}$ (3-methylcyclohexan-1-ol) units, and structurally optimized them using the CASTEP module. The optimized models of the two carbon-impurities are shown in Figure 4.

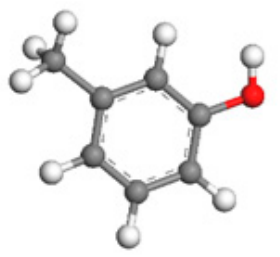

(a)

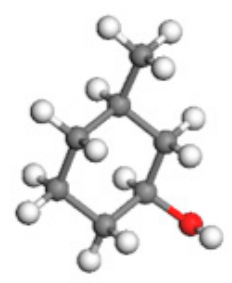

(b)

\section{$\mathrm{C}+\mathrm{H} \odot \mathrm{O}$}

Figure 4. Optimized carbon structural units for the two carbon impurities ((a) $\mathrm{Ph}-\mathrm{OH} ;(\mathbf{b}) \mathrm{C}-\mathrm{OH})$.

\subsubsection{Frontier Orbital Analysis}

According to frontier molecular orbital theory, electrons in the highest occupied and lowest unoccupied molecular orbitals (HOMO and LUMO, respectively) have the highest reactivities [28]. The energy differences of the frontier orbitals of the two carbon structural units and kaolinite were calculated using Equations (2) and (3):

$$
\begin{gathered}
\Delta E_{1}=\left|E_{H O M O}^{\text {surface }}-E_{\text {LUMO }}^{\text {adsorbate }}\right|, \\
\Delta E_{2}=\left|E_{\text {LUMO }}^{\text {adsorbate }}-E_{H O M O}^{\text {surface }}\right|,
\end{gathered}
$$

where $E_{H O M O}^{\text {surface }}$ and $E_{L U M O}^{\text {surface }}$ are the orbital energies of the HOMO and LUMO of the mineral surface, and $E_{H O M O}^{\text {surface }}$ and $E_{L U M O}^{\text {surface }}$ are the orbital energies of the HOMO and LUMO of the coal molecules. Figure 5 shows the results of the energy difference calculations. It can be seen that $\Delta E_{1}>\Delta E_{2}$, which indicates that the HOMO orbitals of the different $\mathrm{O}$-containing structural units of coal may easily react with the orbitals of the kaolinite. 


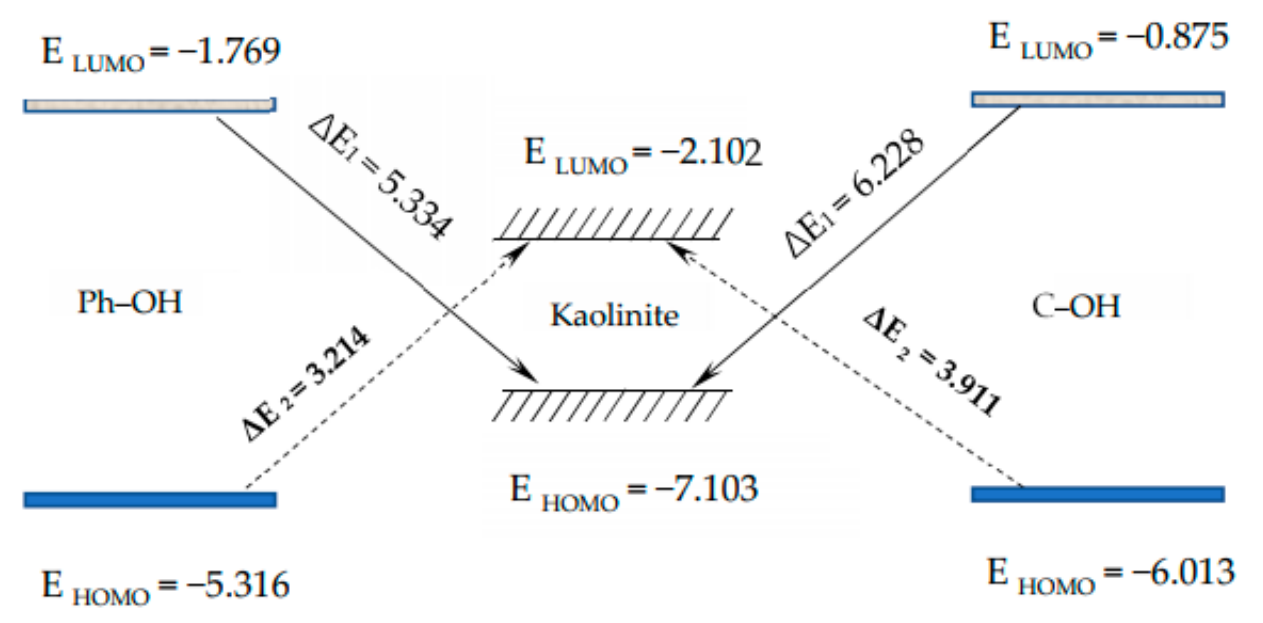

Figure 5. Schematic diagram of the frontal orbital energy of different carbon structural units and kaolinite.

The HOMOs of the two carbon structural units and the LUMO of the kaolinite were constructed for analysis, as shown in Figure 6. Areas in yellow and blue represent spinning $\alpha$ and $\beta$ electrons, which are equivalent. The $\mathrm{HOMO}$ orbital of the $\mathrm{Ph}-\mathrm{OH}$ unit was mainly located in the benzene ring and hydrogen bonds, while the $\mathrm{HOMO}$ orbital of the $\mathrm{C}-\mathrm{OH}$ unit mainly occurred in hydrogen bonds, with a weaker but uniform distribution in the carbon ring. The LUMO orbital of kaolinite mainly occurred on the (001) surface, which suggests that both carbon structural units would be more likely to adsorb on that surface based on frontier molecular orbital theory.

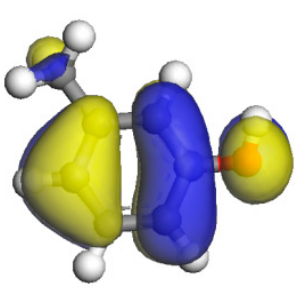

(a)

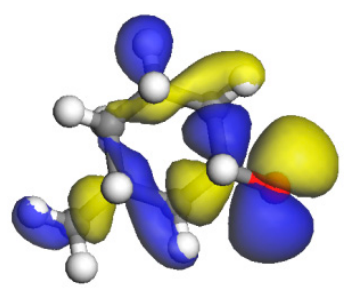

(b)

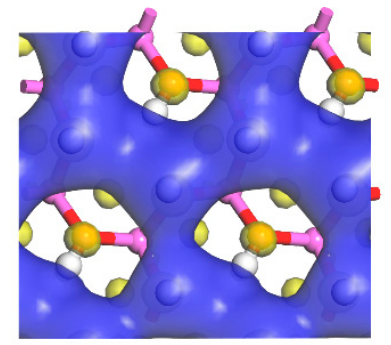

(c)

Figure 6. Frontier orbitals of the two carbon structural units and kaolinite, with the isovalue being 0.02 electrons/Å3. ((a) HOMO (Highest occupied molecular orbital) of $\mathrm{Ph}-\mathrm{OH}$; (b) $\mathrm{HOMO}$ of $\mathrm{C}-\mathrm{OH}$; (c) LUMO (Lowest unoccupied molecular orbital) of kaolinite).

\subsubsection{Analysis of Adsorption Configurations and Adsorption Energies}

DFT calculations were used to simulate the adsorption of the two carbon structural units on the kaolinite surface; the resultant optimum adsorption configurations are shown in Figures 7 and 8 . Both figures reveal that the O-containing functional groups of the two carbon structural units could form hydrogen bonds with the kaolinite surface; furthermore, the benzene ring in the $\mathrm{Ph}-\mathrm{OH}$ unit lay approximately parallel to the surface after it achieved optimum adsorption on the kaolinite surface. This indicates that the benzene ring interacts with the kaolinite surface, a conclusion consistent with those of previous studies $[29,30]$. In contrast, the carbon ring of the $\mathrm{C}-\mathrm{OH}$ unit adopted an approximately perpendicular orientation relative to the surface at its point of optimum adsorption on the kaolinite surface. 
(a)
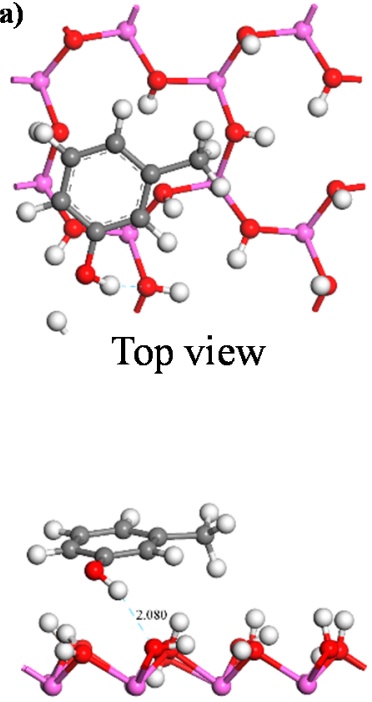

Side view (b)
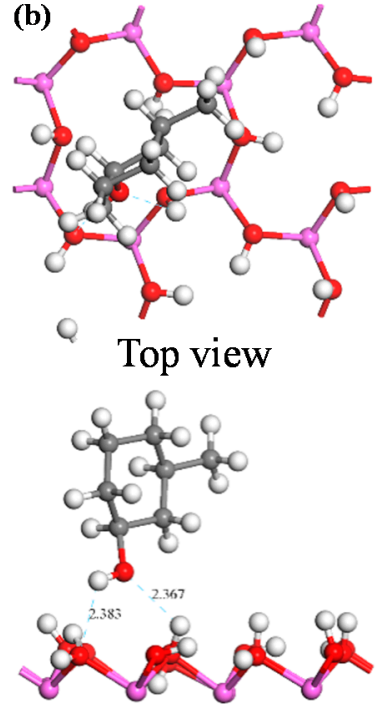

Side view

C OH O O OSi Cal

Figure 7. Optimum adsorption configurations of the two carbon structural units on the kaolinite (001) surface. ((a) $\mathrm{Ph}-\mathrm{OH}$; (b) $\mathrm{C}-\mathrm{OH})$.

(a)
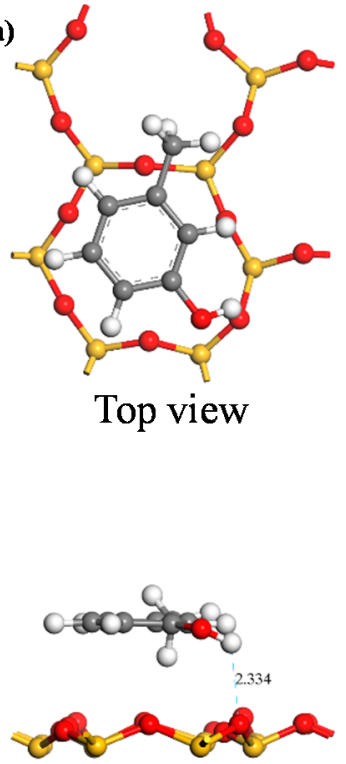

Side view (b)

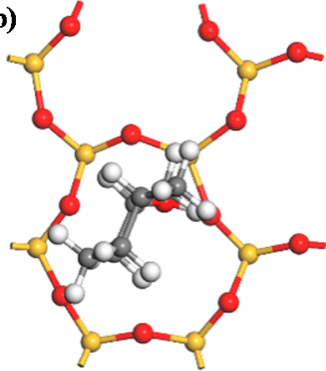

Top view

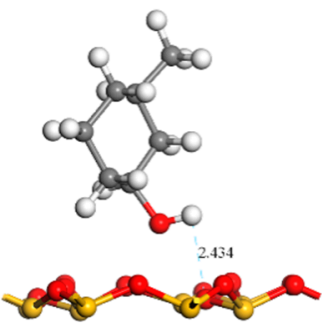

Side view

CC OH OO OSi Cal

Figure 8. Optimum adsorption configurations of the two carbon structural units on the kaolinite $(00 \overline{1})$ surface. ((a) $\mathrm{Ph}-\mathrm{OH}$; (b) $\mathrm{C}-\mathrm{OH})$.

The optimum adsorption configurations of the two carbon structural units on the kaolinite $(001)$ and $(00 \overline{1})$ surfaces show that oxygen-containing functional groups in either unit can form hydrogen bonds with each surface, and that the aromatic ring in the $\mathrm{Ph}-\mathrm{OH}$ unit interacts with both kaolinite surfaces while the carbon ring in the $\mathrm{C}-\mathrm{OH}$ unit does not. For the two optimum adsorption configurations, the Eads of oxygen-containing functional groups in the $\mathrm{Ph}-\mathrm{OH}$ and $\mathrm{C}-\mathrm{OH}$ units were lower on the kaolinite (001) surface than the kaolinite (001) surface (Table 5). In particular, the Eads value of the oxygen-containing functional group in the $\mathrm{Ph}-\mathrm{OH}$ unit on the kaolinite (001) surface 
was the lowest, indicating that the $\mathrm{C}$ elements in the $\mathrm{Ph}-\mathrm{OH}$ unit were more likely to adsorb on the kaolinite (001) surface, which is consistent with the adsorption configuration analysis results.

Table 5. Adsorption energies for the two carbon structural units on the kaolinite (001) and (001) surfaces.

\begin{tabular}{|c|c|c|}
\hline \multirow{2}{*}{ Adsorption Configuration } & \multicolumn{2}{|c|}{ Adsorption Energy Eads/eV } \\
\hline & Kaolinite (001) Surface & Kaolinite $(00 \overline{1})$ Surface \\
\hline $\mathrm{Ph}-\mathrm{OH}$ & -1.19 & -1.02 \\
\hline $\mathrm{C}-\mathrm{OH}$ & -0.78 & -0.55 \\
\hline
\end{tabular}

\subsubsection{Electric Charge Analysis}

Through the analysis of the electron transfer among adjacent atoms in the adsorption system, the adsorption mechanism for the two different structural units of the carbon impurities on the kaolinite surfaces can be illustrated. Electron transfer among adjacent atoms is directly reflected through the construction of electron density maps of the adsorption system.

Figure 9 shows the electron density maps of the optimum adsorption configurations of the two carbon structural units adsorbed on the kaolinite (001) surface. Areas in blue and yellow represent electron aggregation and consumption among adjacent atoms, respectively. From the figure, it can be seen that the electrons from the kaolinite (001) surface were generally transferred to both carbon structural units when they were adsorbed. In the optimum adsorption configuration of the $\mathrm{Ph}-\mathrm{OH}$ unit, electron aggregation and consumption among adjacent atoms occurred not only around the hydroxyl groups that formed hydrogen bonds on the kaolinite (001) surface, but also took place extensively around the methyl group and benzene ring. Thus, the methyl and benzene moieties could also adsorb on the kaolinite (001) surface. In the optimum adsorption configuration of the $\mathrm{C}-\mathrm{OH}$ unit, electron aggregation among adjacent atoms occurred only around the hydroxyl groups that formed hydrogen bonds on the kaolinite (001) surface. In addition, the range of electron transfer among adjacent atoms in the adsorption system of the Ph-OH-on-kaolinite (001) surface was significantly wider than that in the adsorption system of the similarly adsorbed $\mathrm{C}-\mathrm{OH}$ unit. Thus, $\mathrm{Ph}-\mathrm{OH}$ adsorption on the kaolinite (001) surface was stronger than that of the $\mathrm{C}-\mathrm{OH}$ unit, which is consistent with the calculated adsorption energies.

Figure 10 shows similar electron density maps for the optimum adsorption configurations on the kaolinite $(00 \overline{1})$ surface. The adsorption mechanism of the two carbon structural units on this surface appears similar to that on the kaolinite (001) surface. Electrons from the kaolinite $(00 \overline{1})$ surface were generally transferred to both carbon structural units when they were adsorbed. Similar to the preceding discussion, in the optimum adsorption configuration of the $\mathrm{Ph}-\mathrm{OH}$ unit, electron aggregation and consumption among adjacent atoms occurred around the hydrogen-bonding hydroxyl, methyl, and benzene moieties on the kaolinite $(00 \overline{1})$ surface. Thus, the methyl group and benzene ring could also adsorb on the kaolinite $(00 \overline{1})$ surface. In the optimum adsorption configuration of the $\mathrm{C}-\mathrm{OH}$ unit, electron aggregation among adjacent atoms occurred only around the hydroxyl group that formed a hydrogen bond on the kaolinite $(00 \overline{1})$ surface. On the kaolinite $(00 \overline{1})$ surface, too, the range of electron transfer among adjacent atoms in the $\mathrm{Ph}-\mathrm{OH}$ adsorption system was significantly wider than that in the $\mathrm{C}-\mathrm{OH}$ adsorption system, which means that the $\mathrm{Ph}-\mathrm{OH}$ unit was adsorbed more readily and stably on the kaolinite $(00 \overline{1})$ surface compared with the $\mathrm{C}-\mathrm{OH}$ unit. Finally, the range of electron transfer when the $\mathrm{Ph}-\mathrm{OH}$ and $\mathrm{C}-\mathrm{OH}$ units were adsorbed on the kaolinite (001) surface was wider than when the two structural units were adsorbed on the kaolinite $(00 \overline{1})$ surface. Thus, both carbon structural units adsorbed more readily on the kaolinite (001) surface, which is consistent with the results of frontier orbital analysis. 
(a)

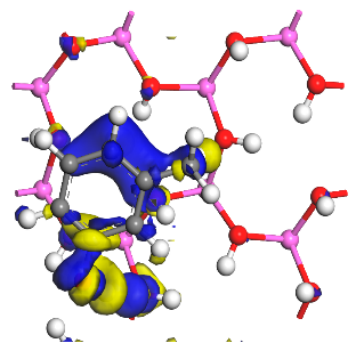

Top

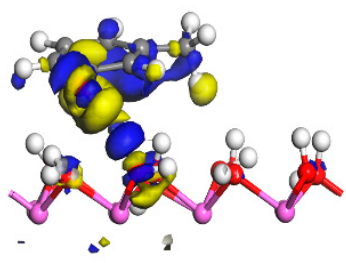

Side view (b)

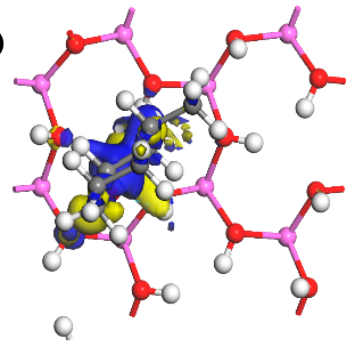

Top view

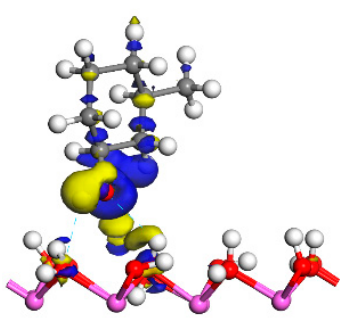

Side view

Figure 9. Electron density differences for the optimum adsorption configurations of the two carbon structural units adsorbed on the kaolinite (001) surface, with the isosurface value being 0.008 electrons $/ \AA^{3}$. ((a) $\mathrm{Ph}-\mathrm{OH} ;(\mathbf{b}) \mathrm{C}-\mathrm{OH})$.

(a)

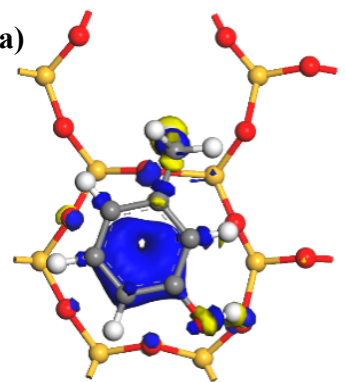

Top view

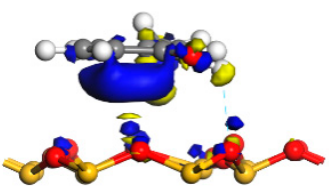

Side view
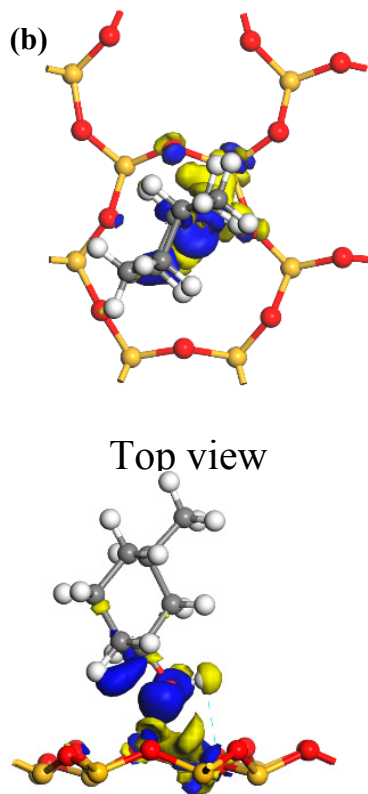

Side view

Figure 10. Electron density differences for the optimum adsorption configurations of the two carbon structural units adsorbed on the kaolinite $(00 \overline{1})$ surface, with the isosurface value being 0.008 electrons $/ \AA^{3}$. ((a) $\mathrm{Ph}-\mathrm{OH} ;(\mathbf{b}) \mathrm{C}-\mathrm{OH})$.

The Mulliken charge populations of the atoms before and after the $\mathrm{Ph}-\mathrm{OH}$ and $\mathrm{C}-\mathrm{OH}$ units were adsorbed on the kaolinite (001) and (001) surfaces are shown in Table 6 . In the optimum adsorption configurations of the adsorbates, the quantities of electric charge transferred from the kaolinite (001) surface to the $\mathrm{Ph}-\mathrm{OH}$ and $\mathrm{C}-\mathrm{OH}$ units were 0.52 e and 0.29 e, respectively, which are both higher than the electric charges of 0.31 e and 0.17 e transferred from the kaolinite $(00 \overline{1})$ surface to these two units. This is consistent with the results from the electron density difference analysis. By combining these 
results with the adsorption energy calculations, it is clear that in the adsorption of the two carbon structural units on the kaolinite surfaces, a greater quantity of electric charge transfer leads to a lower adsorption energy and higher stability in the adsorption system.

Table 6. Mulliken charge populations of the atoms before and after the $\mathrm{Ph}-\mathrm{OH}$ and $\mathrm{C}-\mathrm{OH}$ units were adsorbed on the kaolinite (001) and $(00 \overline{1})$ surfaces.

\begin{tabular}{|c|c|c|c|}
\hline \multirow{2}{*}{ Adsorption Configuration } & \multirow{2}{*}{ Adsorption Status } & \multicolumn{2}{|c|}{ Mulliken Charge/e } \\
\hline & & (001) Surface & $(00 \overline{1})$ Surface \\
\hline \multirow{2}{*}{$\mathrm{Ph}-\mathrm{OH}$} & before & 0 & 0 \\
\hline & after & -0.52 & -0.31 \\
\hline \multirow{2}{*}{ Kaolinite surface } & before & 0 & 0 \\
\hline & after & 0.52 & 0.31 \\
\hline \multirow{2}{*}{$\mathrm{C}-\mathrm{OH}$} & before & 0 & 0 \\
\hline & after & -0.29 & -0.17 \\
\hline \multirow{2}{*}{ Kaolinite surface } & before & 0 & 0 \\
\hline & after & 0.29 & 0.17 \\
\hline
\end{tabular}

The comprehensive analysis of adsorption configurations and charge transfer shows that the adsorption mechanism of the carbon impurities on coal-associated kaolinite surface is the comprehensive result of hydrogen-bond formation between the O-containing functional groups in carbon impurities and kaolinite surfaces, as well as the electrostatic attraction between the aromatic rings on the surface of the carbon impurity and the kaolinite surfaces. This result is similar to the interaction mechanism between coal structural units [29] or amine/ammonium salts $[10,11]$ and kaolinite surface in previous publications, the difference is that the electrostatic attraction and hydrogen bonding contribute differently to the interaction in different systems.

\section{Conclusions}

In this paper, the adsorption of carbon impurities on kaolinite was studied by a combined experimental and computational study. The atrament in coal-associated kaolinite consists of carbon impurities comprised mainly of $\mathrm{C}$ and $\mathrm{O}$. The adsorption of the carbon impurities on the surface of the coal-associated kaolinite is the comprehensive result of hydrogen-bond formation between the O-containing functional groups on the carbon impurities' and kaolinite surfaces as well as the electrostatic attraction between the aromatic rings on the surface of the carbon impurity and the kaolinite surfaces.

Since carbon impurities are a common contaminant type in coal-associated kaolinite, the results of the present study can provide a theoretical basis for the further understanding of actual adsorption on the surface of kaolinite in coal slurries.

Author Contributions: Conceptualization, F.M.; Investigation, F.L.; Methodology, J.C.; Validation, M.Z.; Writing —original draft, F.L.; Writing—review and editing, L.L.

Funding: This research was funded by Natural Science Foundation of China, grant number 51504011 and 51874011. Acknowledgments: The authors would like to thank Zhang Mingxu at Anhui University of Science and Technology for his help with this paper.

Conflicts of Interest: The authors declare no conflict of interest.

\section{References}

1. Chen, J.; Min, F.; Liu, L.; Peng, C.; Lu, F. Hydrophobic aggregation of fine particles in high muddied coal slurry water. Water Sci. Technol. 2016, 73, 501-510. [CrossRef] [PubMed] 
2. Liu, L.; Min, F.; Lu, F.J.; Zhang, M.; Song, S. A novel method for the determination of the point of zero net proton charge of colloidal kaolinite in aqueous solutions. Surf. Rev. Lett. 2016, 23, 1650023. [CrossRef]

3. Israelachvili, J.N.; McGuiggan, P.M. Forces between surfaces in liquids. Science 1988, 241, 795-800. [CrossRef] [PubMed]

4. Peng, C.; Song, S.; Fort, T. Study on hydration layers near a hydrophilic surface in water through AFM imaging. Surf. Interface Anal. 2006, 38, 975-980. [CrossRef]

5. Liu, L.; Shen, L.; Li, W.; Min, F.; Lu, F. Study on the aggregation behavior of kaolinite particles in the presence of cationic, anionic and non-ionic surfactants. PLoS ONE 2018, 13, e0204037. [CrossRef]

6. Cui, J.R.; Fang, Q.X.; Huang, G.Z. Crystal structures and surface properties of diaspore and kaolinite. Nonferrous Met. 1999, 51, 25-30.

7. Jiang, H.; Sun, Z.; Xu, L.; Hu, Y.; Huang, K.; Zhu, S. A comparison study of the flotation and adsorption behaviors of diaspore and kaolinite with quaternary ammonium collectors. Miner. Eng. 2014, 65, 124-129. [CrossRef]

8. Perdew, J.P.; Kurth, S. Density functionals for non-relativistic coulomb systems in the New Century. Lect. Notes Phys. 2003, 620, 1-51.

9. Wang, X.; Qian, P.; Song, K.; Zhang, C.; Dong, J. The DFT study of adsorption of 2, 4-dinitrotoluene on kaolinite surfaces. Comput. Theor. Chem. 2013, 1025, 16-23. [CrossRef]

10. Liu, L.; Min, F.; Chen, J.; Lu, F.; Shen, L. The adsorption of dodecylamine and oleic acid on kaolinite surfaces: Insights from DFT calculation and experimental investigation. Appl. Surf. Sci. 2019, 470, 27-35. [CrossRef]

11. Chen, J.; Min, F.; Liu, L.; Liu, C.; Lu, F. Experimental investigation and DFT calculation of different amine/ammonium salts adsorption on kaolinite. Appl. Surf. Sci. 2017, 419, 241-251. [CrossRef]

12. Zhao, H.; Wang, B.; Li, Y.; Song, Q.; Zhao, Y.; Zhang, R.; Hu, Y.; Liu, S.; Wang, X.; Shu, X. Effect of chemical fractionation treatment on structure and characteristics of pyrolysis products of Xinjiang long flame coal. Fuel 2018, 234, 1193-1204. [CrossRef]

13. Clark, S.J.; Segall, M.D.; Pickard, C.J.; Hasnip, P.J.; Probert, M.I.; Refson, K.; Payne, M.C. First principles methods using CASTEP. Z. Krist. 2005, 220, 567-570. [CrossRef]

14. Perdew, J.P.; Burke, K.; Ernzerhof, M. Generalized gradient approximation made simple. Phys. Rev. Lett. 1996, 77, 3865-3868. [CrossRef] [PubMed]

15. Vanderbilt, D. Soft self-consistent pseudopotentials in a generalized eigenvalue formalism. Phys. Rev. B 1990, 41, 7892-7895. [CrossRef]

16. Han, Y.; Liu, W.; Chen, J.; Han, Y. Adsorption mechanism of hydroxyl calcium on two kaolinite (001) surface. J. China Coal Soc. 2016, 41, 743-750.

17. Zhang, G.; Al-Saidi, W.A.; Myshakin, E.M.; Jordan, K.D. Dispersion-corrected density functional theory and classical force field calculations of water loading on a pyrophyllite(001) surface. J. Phys. Chem. C 2012, 116, 17134-17141. [CrossRef]

18. Monkhorst, H.J.; Pack, J.D. Special points for Brillouin-zone integrations. Phys. Rev. B 1976, 13, 5188-5192. [CrossRef]

19. Hu, X.L.; Michaelides, A. Water on the hydroxylated (001) surface of kaolinite: From monomer adsorption to a flat 2D wetting layer. Surf. Sci. 2008, 602, 960-974. [CrossRef]

20. Bish, D.L. Rietveld refinement of the kaolinite structure at 1.5 K. Clays Clay Min. 1993, 41, 738-744. [CrossRef]

21. Hu, Y.; Liu, L.; Min, F.; Zhang, M.; Song, S. Hydrophobic agglomeration of colloidal kaolinite in aqueous suspensions with dodecylamine. Colloids Surf. A Physicochem. Eng. Asp. 2013, 434, 281-286. [CrossRef]

22. Liu, F.R.; Li, W.; Guo, H.Q.; Li, B.Q.; Bai, Z.Q.; Hu, R.S. XPS study on the change of carbon containing groups and sulfur transformation on coal surface. J. Fuel Chem. Technol. 2011, 39, 81-84.

23. Shen, L.; Min, F.; Liu, L.; Zhu, J.; Xue, C.; Cai, C.; Zhou, W.; Wang, C. Application of gaseous pyrolysis products of the waste cooking oil as coal flotation collector. Fuel 2019, 239, 446-451. [CrossRef]

24. Shi, Q.; Qin, B.; Liang, H.; Gao, Y.; Qu, B. Effects of igneous intrusions on the structure and spontaneous combustion propensity of coal: A case study of bituminous coal in Daxing Mine, China. Fuel 2018, 216, 181-189. [CrossRef]

25. Zhao, H.; Song, Q.; Liu, S.; Li, Y.; Wang, X.; Shu, X. Study on catalytic co-pyrolysis of physical mixture/staged pyrolysis characteristics of lignite and straw over an catalytic beds of char and its mechanism. Energy Convers. Manag. 2018, 161, 13-26. [CrossRef] 
26. Kelemen, S.R.; Afeworki, M.; Gorbaty, M.L.; Cohen, A.D. Charact erization of organically bound oxygen forms in lignites, peats, and pyrolyzed peats by X-ray photoelectron spectroscopy (XPS) and solid-state 13C NMR methods. Energy Fuels 2002, 16, 1450-1462. [CrossRef]

27. Yang, Z.; Zhou, A.; Zhang, H.; Zhang, Q. XPS analysis of Shenfu coal with different density fraction under UV catalytic photo oxidation. J. China Univ. Min. Technol. 2010, 39, 98-103.

28. Chen, J.H. The Solide Physics of Sulphide Minerals Flotation; Central South University Press: Changsha, China, 2015; pp. 61-62.

29. Chen, J.; Min, F.; Liu, L. The interactions between fine particles of coal and kaolinite in aqueous, insights from experiments and molecular simulations. Appl. Surf. Sci. 2019, 467-468, 12-21. [CrossRef]

30. Li, B.; Liu, S.; Guo, J.; Zhang, L. Interaction between low rank coal and kaolinite particles: A DFT simulation. Appl. Surf. Sci. 2018, 456, 215-220. [CrossRef]

(C) 2019 by the authors. Licensee MDPI, Basel, Switzerland. This article is an open access article distributed under the terms and conditions of the Creative Commons Attribution (CC BY) license (http://creativecommons.org/licenses/by/4.0/). 